 \\ A VIBEYOR

\section{Mosaic Landscape Pattern Explains Vegetation Resistance to High Fire Frequency in Corsica over the Last Six Millennia}

\author{
Bérangère Leys ${ }^{1,2^{*}}$, Thomas Curt ${ }^{3}$ and Che Elkin ${ }^{4}$ \\ ${ }^{1}$ Department of Geography, Kansas State University, USA \\ ${ }^{2}$ Chrono-environnement UMR6249, CNRS, Univ. Bourgogne Franche-Comte, France \\ IIRSTEA, UR RECOVER, France \\ ${ }^{4}$ University of Northern British Columbia, Prince George, Canada
}

\begin{abstract}
Summary
1. Significant pine mortality has been observed in mountainous areas with a Mediterranean climate over recent decades, impacting ecosystem function and economic management of these forests. Despite this, few studies have examined how forest management can interact with disturbances to influence pine mortality.

2. We used process-based models to quantify the spatial distribution of a typical vegetation assemblage of Corsican pine forests, and evaluate how different landscape patterns and fire regimes (i.e. burned area and fire intensity) affect plant communities. For all 18 scenarios examined, fire return interval was fixed at 100 \pm 70 years that corresponded to the mean \pm standard deviation reconstructed for the last 6000 years in this ecosystem.

3. Results indicate that the most species diverse Corsican pine ecosystems over the past 6000 years of history are best explained by a high fire frequency of small fires that cover a large area in total in a climate comparable with today. An increase in mean annual temperature of 1 or $2{ }^{\circ} \mathrm{C}$ is sufficient to decrease the diversity of the ecosystem. In addition, a mosaic landscape pattern is correlated with high plant species diversity, and is associated with medium to low fire intensity, and small burned areas ( 3 to $5 \%$ of the landscape).

4. Synthesis and applications: The diversity of the Corsican pine forest as recorded in the past 6000 years is likely explained by frequent fires of medium to low intensity. Thus, we encourage pine forest management in Corsica (and in the Mediterranean mountain belt) to use frequent disturbances, such as clear felling, to promote a mosaic landscape that facilitates species diversity and presence of Corsican black pine.
\end{abstract}

\section{Keywords}

Corsican black pine, Fire ecology, Frequent disturbances, Landscape pattern

\section{Introduction}

Vegetation dynamics and species assemblages are driven both by climate and fire in many Mediterranean areas [1], where the warm and dry seasonal conditions facilitate ignition of vegetation. The Mediterranean Basin is well known for its high fire proneness [2] and its moderately high fire frequency [3]. Indeed, Mediterranean-type ecosystems and landscapes have been shaped in part by the fire regime, defined as the combined effects of fire intensity and frequency, and area burned [3]. In this context, studies on post-fire vegetation responses and succession have contributed to our understanding of the factors that influence the resistance or resilience of vegetation to fire [4-7]. Such studies have been used as the basis for modelling research that examines how vegetation dynamics interact with disturbances in the context of climate change [8-10].

The models' outputs provide important knowledge

*Corresponding author: Bérangère Leys, Department of Geography, Kansas State University, USA ; Chrono-environnement UMR6249, CNRS, Univ Bourgogne Franche-Comte, 25000 Besancon, France, E-mail: berangereleys@gmail.com Received: November 30, 2017: Accepted: March 24, 2018: Published: March 26, 2018

Copyright: $\odot 2018$ Leys B, et al. This is an open-access article distributed under the terms of the Creative Commons Attribution License, which permits unrestricted use, distribution, and reproduction in any medium, provided the original author and source are credited. 

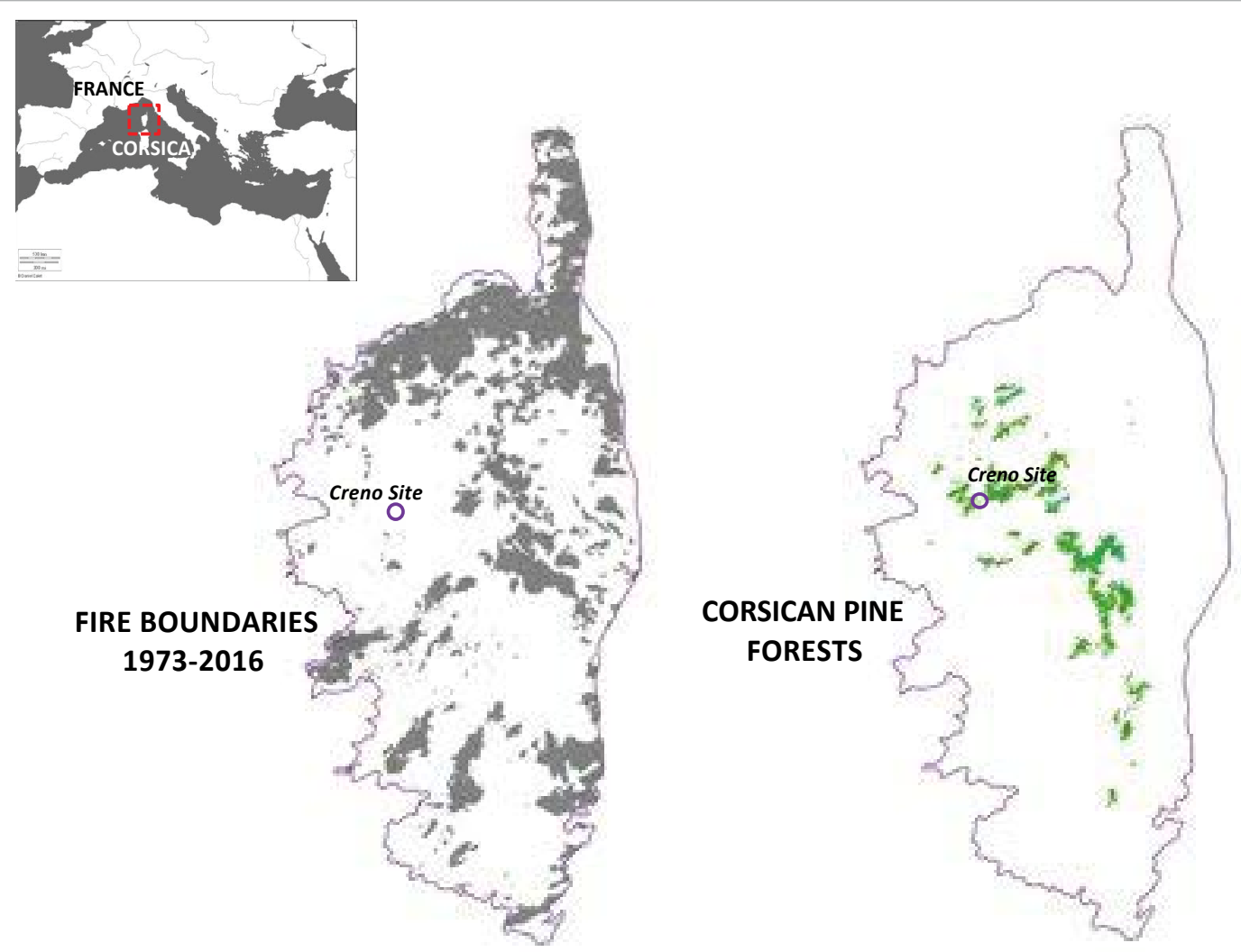

Figure 1: Locations of areas burned in Corsica from 1973 to 2013, and the distribution of Corsican pine forests.

for managing forests in these fire-prone ecosystems. However, published papers on Mediterranean areas have been focused on oak forests at low elevations $[8,10]$, with a lack of management-focused studies on the mountain belt vegetation assemblages in the Mediterranean $\mathrm{Ba}$ sin. Corsica harbours several endemic species, including the Corsican black pine (Pinus nigra subsp. laricio hereafter P. laricio) that covers 16,000 ha of woodlands in the montane belt of Corsica (Figure 1) [11]. Model-based studies suggest that the natural area of $P$. laricio is altered by natural disturbances (wildfires) and by human activities (logging and managed fires) [11,12]. Although this species is protected by European law (Directive habitat faune flore regulation, 1992) because it is a key habitat for the Corsican nuthatch (Sitta whiteheadi), an endangered bird, forestry in the area has focused on increasing P. laricio timber production and harvesting. Moreover, its future distribution is possibly threatened by logging and increased climate- and human-induced fire risks (Figure 1). Research on the management of Canadian boreal forests has indicated that replacing the natural disturbance regime by clear felling can allow ecosystem functioning and economic efficiency to be maintained $[13,14]$. More studies are thus needed to understand the natural range of disturbances experienced by the Corsican pine forests, to better manage them in the future.

The study by Leys, Finsinger \& Carcaillet [15] revealed 18,000 years of local fire and vegetation history of a Mediterranean mountain site in Corsica characterized by $P$. laricio forest, and highlighted, a high fire frequency
$(100 \pm 70(\mathrm{SD})$ years between two fires) over the last 6000 years. This showed a continuous presence of trees and shrubs taxa, including Pinus laricio, Abies alba, Fagus sylvatica, Juniperus communis, and Erica multiflora. The authors concluded that the vegetation was adapted or resistant to fire, thereby supporting present-day observations of birch and beech post-fire behaviour [16]. They noted that no stand-replacing fires occurred during the 18,000 years over which the Corsican pine was recorded. However, a short fire-return interval (30 years between two fires) was indicated, suggesting that either fire intensity was low or that burned areas were small [17] given the poor resistant of the Corsican black pine to fire. This study constituted the first record of long-term fire frequency reconstructed in Mediterranean ecosystems dominated by Corsican black pines. However, the relationship between the vegetation and the fire regime was unclear, including the impact of the fire intensity and the extent of the area burned on the vegetation diversity and its long-term resistance.

In our study, we aimed to test which component of the fire regime, including fire frequency, fire intensity, and area burned, best explain the stability of the Corsican pine ecosystem over the last 6000 years. The results would help to define baselines of ecosystem functioning and guidelines for stakeholders and forest managers of Mediterranean pine systems. To do so, we used two mechanistic and spatially-explicit models: The LandClim model to simulate plant species diversity under different 
climates and fire regimes [9], and the LASS model to account for different landscape patterns and fire parameters [18]. Specifically, we tested the role and the importance of (i) landscape pattern of forests, (ii) Vegetation structure, and (iii) Size and intensity of fire at a known fire frequency.

\section{Materials and Methods}

\section{Mediterranean mountain belt vegetation assem- blages - LandClim model}

The mountain vegetation belt is characterised in Corsica by Pinus. laricio (Figure 1B), Fagus sylvatica, Abies alba, Alnus cordata, Betula pendula, Quercus petraea, Q. ilex and Q. pubescens in the tree layer and Juniperus communis (ssp communis and ssp nana) and Ericaceae (Erica arborea, E. scoparia and E. multiflora) in the shrub layer [19]. These species constitute the available fuel for fire.

The plant assemblages reconstructed for the past 6000 years at the Creno site (Corsica, France, Figure 1) are derived from the identification of plant macroremains (plant parts preserved in the sediment core extruded at Creno lake, more details in Leys, Finsinger \& Carcaillet 2014) [15] that allows for an accurate reconstruction of ligneous taxa at the local scale for the time period considered (6000 years of history here). However, some species possibly present in the landscape may not have been recorded in the past for a short (few years) or a longer period (several centuries) of time because of their small proportional representation in the landscape, or because their geographical position change in colder of drier climate conditions during the last 6000 years and they were below the depository environment at this time.

To avoid this bias, we used common species assemblages present at this elevation under a Mediterranean climate that we simulated under different climatic conditions and different fire frequencies, using the vegetation model LandClim [9,20-22]. The basic structure of LandClim consists of a local model that simulates forest succession for each cell (usually $25 \times 25 \mathrm{~m}$ ) on the landscape at a yearly time step, and a landscape model that simulates spatial processes of fire operating over several cells, at 10-year time steps. Simulations were performed using three temperature permutations $\left(0^{\circ} \mathrm{C},+1{ }^{\circ} \mathrm{C}\right.$, + $2{ }^{\circ} \mathrm{C}$ ) compared with current mean annual temperature, and 6 fire-frequency treatments (from no fire to extreme).

In the model, a number of fire ignitions within each decade are assumed to occur at randomly selected locations to mimic lightning caused ignitions. A fire is simulated only if it can spread to a neighboring cell (i.e., the four adjacent cells and four diagonal cells). Whether a neigboring cell will burn depends on a fire spread probability, which represents the cell's susceptibility to fire.
Thus, a fire can spread in the model until it stops expanding in all directions, or it reaches the boundaries of the landscape [20]. Fire ignition and spread is a function of the moisture content of vegetation and fuel (a drought index). We link the drought index of a cell to the probability of a fire starting (after a randomly placed ignition event) and spreading and we defined 6 fire treatments from no fire to extreme fire. The fire occurrence values result in a high spread probability for the extreme fire mode to a null spread probability for the no fire mode.

We then compared the assemblages after each simulation with the overall presence and mean relative abundance of species observed in the plant macroremain assemblages (Table 1).

\section{Landscape patterns - LASS model}

Based on the LandClim outputs, we defined vegetation assemblages as composed of 5 tree species (Pinus laricio, Abies alba, Fagus sylvatica, Quercus and Betula), two shrub species (Erica, Cistus spp.) and resprouting herbs (e.g. graminoids like Brachypodium). The proportion of each species was defined using field data plots in the Mediterranean Basin [23]. We calibrated the plant traits (age, height growth, postfire regeneration ability) based on field data in similar vegetation types in southern France [24].

The landscape was first incremented following three different landscape patterns: (1) 'Random' with species located randomly, (2) 'Ecotone' with species located along a gradient, with trees (i.e. pines and oaks) and tall shrubs (i.e. Juniperus and Erica) dominating a part of the landscape and herbs and small shrubs dominating the other part of the landscape as it is observed in managed Corsican pine forests; and (3) 'Mosaic' with species distribution based on field measurements of non-managed landscapes in the Mediterranean Basin [23].

\section{Fire parameters - LASS model}

Fire frequency was derived from a reconstruction of fire episodes over the last 6000 years at the Creno site [15]. The record showed a mean fire return interval of 90 years, with variability ranging from 30 to 200 years between any two fires. The number of years between two fires was thus randomly selected between 30 to 200 years. Fire frequency was the only parameter varying in each run. Thus, we decided to repeat each scenario 50 times to fully encompass the variations in fire frequency over 1000 years of history. Fire was set randomly within each landscape and burned according to the quantity and location of vegetation fuels with the landscape. Fire propagation was limited by the vegetation cover and biomass accumulated since the previous fire [25].

We tested the effect of 1) Fire intensity through the fire severity on vegetation (as explained below), and 2) The 


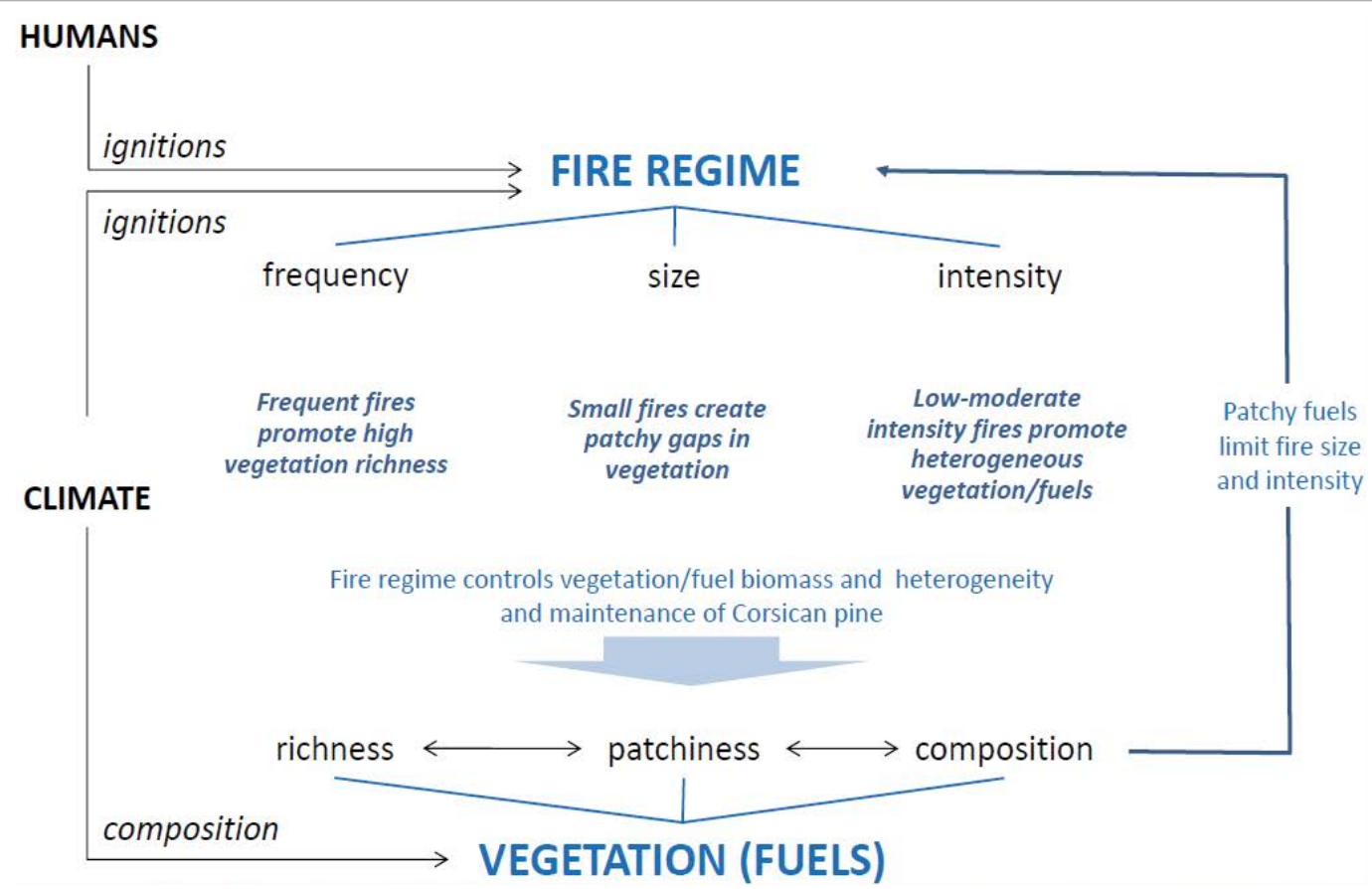

Figure 2: Conceptual diagram of the impacts of each parameter tested on vegetation assemblages and dynamics. The parameters tested in the LASS model were A) Three types of landscape patterns; B) Three levels of fire intensity; and C) Two sizes of area burned. These were applied to vegetation composed of the 7 dominant taxa (Pinus nigra ssp laricio, Fagus sylvatica, Abies alba, Juniperus sp., Erica sp., Quercus ilex and Quercus pubescens). The time between fires for each run was randomly drawn from a uniform distribution spanning 30 to 200 years, in a 1000 year-window simulation.

area burned on plant species diversity, heterogeneity of plant cover and proportion, and the maintenance of species richness over 1000 years of simulation time (Figure 2). In total, 18 scenarios were tested.

Three levels of fire intensity were implemented: Low, medium, and high. In LASS, fire intensity was calculated through the impact on species (i.e. fire severity). Each species thus reacts or dies specifically in response to a given fire intensity according to its fire resistance (linked to plant traits such as bark thickness), its resprouting ability and its postfire ability to recruit from seeds resilience, $[18,26]$. The level of severity is relative from one species to another for each of the three parameters (fire resistance, resprouting, and seeds recruiting).

The area burned was defined as the maximum area able to burn in a given landscape, and is limited in the first place by the quantity of fuel available and the possibility of fire spreading in the landscape (fuel-limited fires). It this study, we tested two levels: 1) A small area burned ( 3 to $5 \%$ of the landscape) as it is recorded today for wildfires in the north-facing Corsican mountains [8], and 2) A large area burned (up to $90 \%$ of the landscape) as it occurs in the lowlands and uncontrolled human-caused fires (Figure 1A).

\section{Statistical analysis of the outputs}

The species assemblages were tested between the output of LandClim model and the plant macroremain assemblages from simulation runs based on an unlim- ited fire size, with 10,000 permutation tests performed per time period, and a full species set. The reconstructed data using 1000-year brackets was used. The percentage of simulations when each model provided the best fit to the reconstructed data per time period was calculated. The main outputs of the LASS modelling were the abundances of each species cohort within each $10-\mathrm{m}$ pixel of the landscape at 100-year time steps and at the end of simulations (1000 years). In addition, LASS computed a Shannon diversity index [27], and a richness value [16]. An index of the propagation of fire for each run representing the propensity of the landscape to spread the fire is also evaluated by the model LASS, and resumed as a contagion index (CONTAG). A Hill and Smith analysis [28] was used to decipher relationships among the vegetation assemblages, diversity index, and fire parameters.

\section{Results and Discussion}

\section{High fire frequencies are required to maintain the Corsican pine forest}

When taking into account the potential plant species assemblages at the mountain belt elevation in Corsica, the LandClim outputs of the simulations confirmed that plant species diversity and abundance is explained by an extremely high fire frequency (highest value of ignition and spread of the fire in the landscape), and a mean annual temperature similar to the present one (Table 1). The model is based on fixed unlimited nutrient resource, a re-load of the species set at each time step of the simu- 


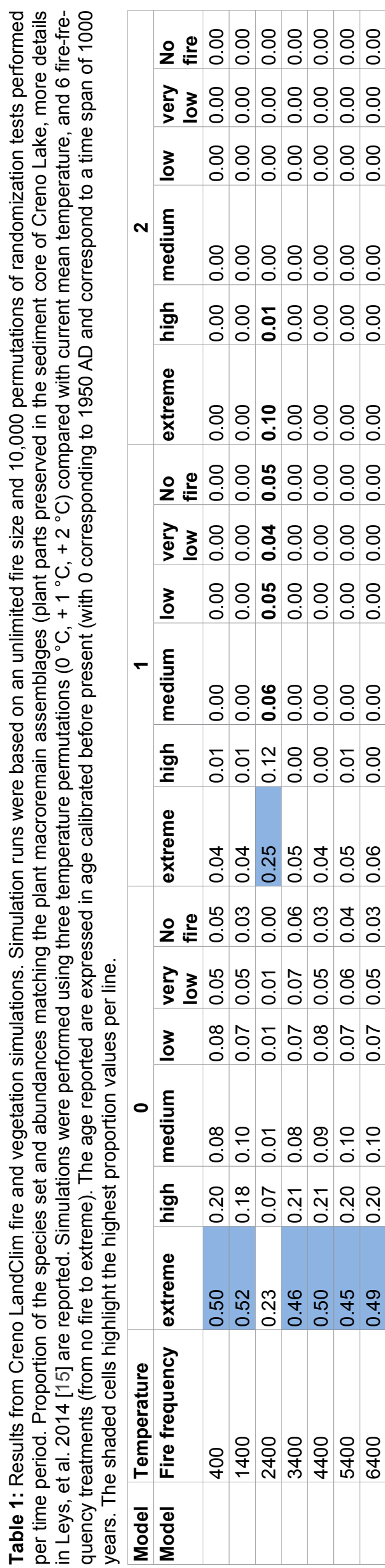

lation, and it accounts for the competition for light from each species. In this context, it is not surprising to have extreme conditions of disturbances matching the maximum richness state, and to have the no fire and low fire conditions associated with a few dominant species in the landscape.

However, a change of only $1-2{ }^{\circ} \mathrm{C}$ in the mean annual temperature is sufficient to impact the vegetation, and to decrease the diversity of the plant assemblages. The main result from this model thus confirms that a high frequency of disturbance is associated with a higher plant species diversity, likely due to a decrease in the competition for light, all parameters being equal. But it also highlights that the temperature is driving vegetation composition on Corsica. For all fire frequencies tested, an increase in temperature corresponds to a decrease in plant species to a total absence of plant species at $2{ }^{\circ} \mathrm{C}$ difference (Table 1 ) that seems to indicate the climate in Corsica would likely have been in the same range of variation as today.

Considering future climate change, it is likely that species richness will decline, and the landscape will homogenize. The interaction between human activities and fire occurrences will be important for the maintenance of species richness and to compensate for the sensitivity of a slight change in the mean annual temperature of the Corsican black pine (Figure 1A) and the current plant assemblages in these areas.

\section{Species richness and landscape pattern}

The quantitative part of the Hill and Smith analysis highlighted two trends (Figure 3A): The first axis is best explained by species abundance, richness and the Shannon index, whereas the second axis is explained by the abundance of Ericaceae species and the propensity of the landscape to spread fire (contag).

The categorical parameters of the Hill and Smith analysis (Figure 3B) follow the same ordination as the species and the landscape indices presented above. The landscape patterns are distinct from each other, with the mosaic landscape pattern corresponding to the positive values of the first axis, the random landscape pattern on the negative values of the first axis, and the ecotone landscape pattern on the positive values of the second axis. The mosaic landscape pattern is thus correlated with species richness, Shannon index, and abundance of most of the taxa. The ecotone landscape is correlated with the ericaceous taxa, and is the pattern with the maximum likelihood of fire spread. Finally, the random pattern is associated with the lowest richness and abundance of taxa.

Taken together, both the abundance of species and species richness are explained by the landscape pattern. They are positively associated with the heterogeneity and the plant species diversity of the landscape (vegetation 
mosaic landscape pattern and Shannon index), and the intermediate to low propensity for fire spread across the landscape. The shrub layer (Ericaceae abundance) seems to be a crucial factor in the spread of fires, probably because it increases connectivity of the vegetation in the landscape. This is also confirmed by the ecotone and the random landscape patterns favouring the greatest spread of fires because of the continuum of vegetation allowing the fire to spread easier. At the opposite end, the mosaic landscape is the landscape characteristic that most influences vegetation abundance and richness. This landscape pattern also displays the lesser propensity for fire spread. The lack of fuel connectivity in the landscape is the most logical explanation for this result, and explains why the mosaic pattern is the standard pattern in the Mediterranean environment.

The Corsican pine forests are mostly managed for timber production with fire suppression politics resulting in monospecific forests, spatially connected by their canopies [29], favouring the spread of fires as modelled for the ecotone landscape. To increase species richness and to promote more old-growth Corsican pines, which constitute the habitat of the Corsican nuthatch, the forest has to return to its mosaic species distribution pattern (Figure 2).

\section{Fire intensity and area burned}

The other two categorical parameters representing parts of the fire regime (fire intensity and size of the area burned) are not significantly different from one another (Figure 3B) on the ordination plot. However, the low and medium fire intensity ellipsoids are larger than the high fire intensity, and include more of the positive values of the first axis of the ordination plot. The area burned is not significantly different either, but the large-areaburned ellipsoid covers the right side of the ordination plot, whereas the small-area-burned ellipsoid covers the left part of the plot.

Altogether, low and medium fire intensities are more highly correlated with the mosaic landscape pattern and the projected maximum species richness and the species abundance values, and they are characterized by larger fires than the random landscape pattern. The ecotone landscape pattern is more associated with higher intensity fires with no difference in the size of the area burned.

For natural Mediterranean environments, our results indicate that high diversity is associated with disturbance-driven landscape heterogeneity, such as the mosaic landscape we tested. This pattern does not favour the spread of fires, but still allows infrequent large fires to occur. Fire intensity reaches a low or medium level that allows some clearance of the landscape thereby enhancing species diversity and abundances. From a management point of view, the maintenance of such an ecosystem, bearing the threatened Corsican black pine, should promote a mean disturbance frequency of 90 years between fires or clear cutting on average, with significant biomass
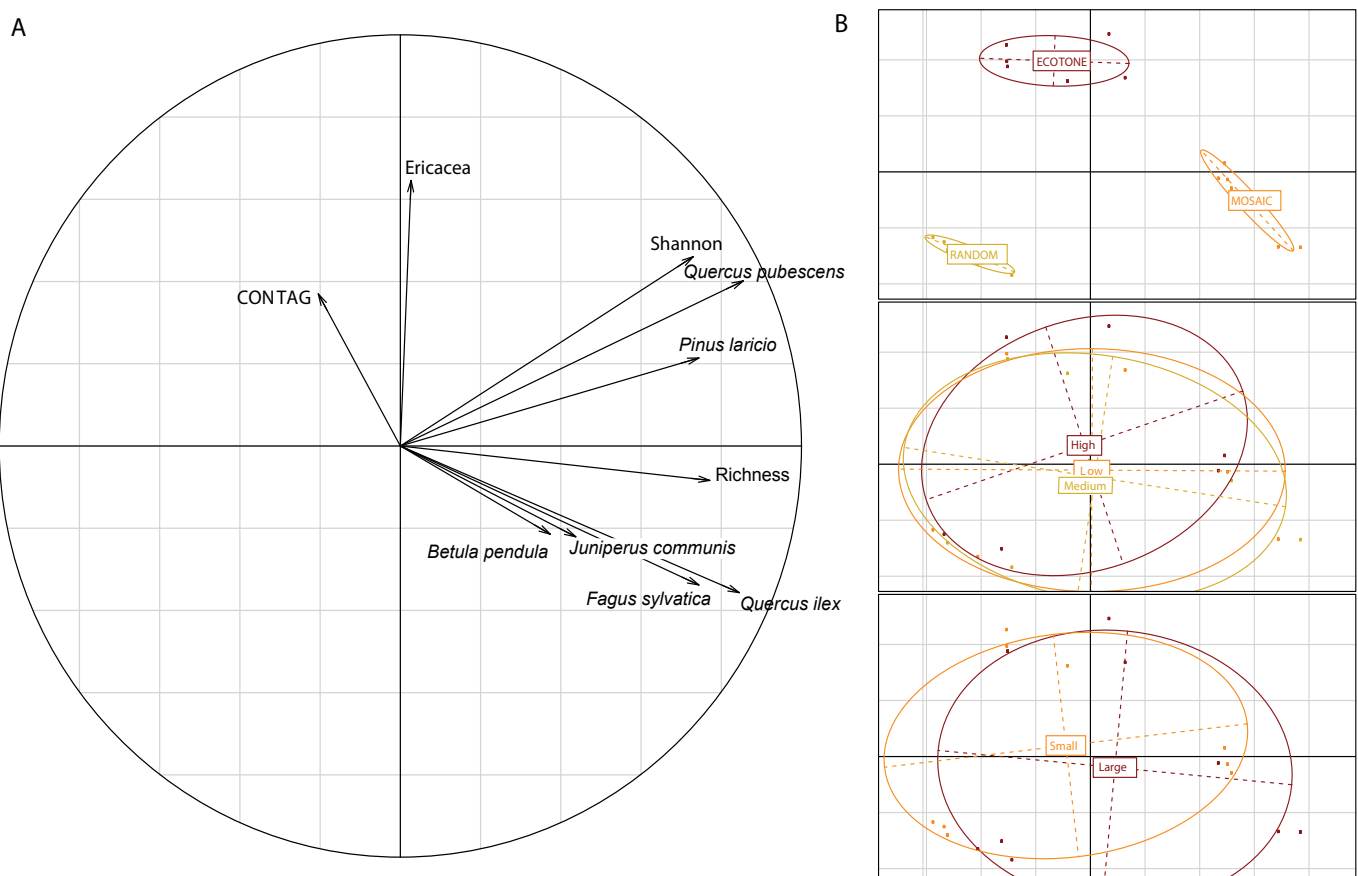

Figure 3: Relationship among vegetation assemblages and fire parameters for 18 scenarios. A) Hill and Smith analysis with the Shannon index of richness, the abundance of each species (number of individuals at the end of the 1000 years of simulation for each scenario) including Pinus nigra ssp laricio, Fagus sylvatica, Abies alba, Juniperus sp., Erica sp., Quercus ilex and Quercus pubescens, and the fire spread index (CONTAG) averaged between the 50 iterations per scenario; B) The same axes 1 and 2 with the qualitative parameters, landscape pattern, fire intensity, and area burned, highlighted respectively. The ellipsoids represent the extant of the output values for each of the parameter, and the centre of the ellipsoid, the mean value. 
removed from a maximum of $80 \%$ of the landscape over a 70 to 200 -year cycle.

\section{Acknowledgments}

We thank the Office National de Forets (ONF) for sharing its experience and knowledge about the Corsican black pine stands. We are grateful to C. Henriot for his advice and insights and to E. Danny for his invitation to submit to this journal. We warmly thank B. Lamont for its comments and suggestions, which significantly improved the manuscript.

\section{References}

1. Bond WJ, Woodward FI, Midgley GF (2005) The global distribution of ecosystems in a world without fire. New Phytologist 165: 525-538.

2. Keeley JE, Pausas JG, Rundel PW, Bond WJ, Bradstock RA (2011) Fire as an evolutionary pressure shaping plant traits. Trends in Plant Science 16: 406-411.

3. Pausas JG, Keeley JE (2009) A burning story: the role of fire in the history of life. Bioscience 59: 593-601.

4. Pausas JG (1999) Mediterranean vegetation dynamics: modeling problems and functional types. Plant Ecology 140: 27-39.

5. Thompson I, Mackey B, McNulty S, Mosseler A (2009) Forest resilience, biodiversity, and climate change. A synthesis of the biodiversity/resilience/stability relationship in forest ecosystems. Secretariat of the Convention on Biological Diversity, Montreal. Technical Series.

6. Willis KJ, Bailey RM, Bhagwat Sa, Birks HJB (2010) Biodiversity baselines, thresholds and resilience: testing predictions and assumptions using palaeoecological data. Trends Ecol Evol 25: 583-591.

7. Enright NJ, Fontaine JB, Lamont BB, Miller BP, Westcott VC (2014) Resistance and resilience to changing climate and fire regime depend on plant functional traits. Journal of Ecology 102: 1572-1581.

8. Mouillot F, Ratte JP, Joffre R, Moreno JM, Rambal S (2003) Some determinants of the spatio-temporal fire cycle in a mediterranean landscape (Corsica, France). Landscape Ecology 18: 665-674.

9. Schumacher S, Bugmann $\mathrm{H}$ (2006) The relative importance of climatic effects, wildfires and management for future forest landscape dynamics in the Swiss Alps. Global Change Biology 12: 1435-1450.

10. Henne PD, Elkin C, Colombaroli D, Samartin S, Bugmann $\mathrm{H}$, et al. (2013) Impacts of changing climate and land use on vegetation dynamics in a Mediterranean ecosystem: insights from paleoecology and dynamic modeling. Landscape Ecology 28: 819-833.

11. Barbet-Massin M, Jiguet $F$ (2011) Back from a predicted climatic extinction of an Island endemic: a future for the corsican nuthatch. PLoS One 6: e18228.

12. Kerr G (2000) Natural regeneration of Corsican pine (Pinus nigra subsp. laricio) in Great Britain. Forestry 73: 479-488.

13. Bergeron Y, Leduc A, Harvey BD, Gauthier S (2002) Natural fire regime: $A$ guide for sustainable management of the Canadian boreal forest. Silva Fennica 36: 81-95.
14. Bergeron $Y$, Vijayakumar IP, Babu D, Ouzennou $H$, Raulier F, et al. (2017) Projections of future forest age class structure under the influence of fire and harvesting: implications for forest management in the boreal forest of eastern Canada. Forestry: An International Journal of Forest Research 90: 485-495.

15. Leys B, Finsinger W, Carcaillet C (2014) Historical range of fire frequency is not the Achilles' heel of the Corsican black pine ecosystem. Journal of Ecology 102: 381-395.

16. Pausas JG (2006) Simulating Mediterranean landscape pattern and vegetation dynamics under different fire regimes. Plant Ecol 187: 249-259.

17. Henne PD, Elkin C, Colombaroli D, Samartin S, Bugmann $\mathrm{H}$, et al. (2012) Impacts of changing climate and land use on vegetation dynamics in a Mediterranean ecosystem: insights from paleoecology and dynamic modeling. Landscape Ecology 28: 819-833.

18. Pausas JG, Ramos Jl (2006) Landscape analysis and simulation shell (LASS). Environmental Modelling \& Software 21: 629-639.

19. Gamisans J, I Badia JN, I Rafols ES (2000) La Végétation de La Corse. Edisud.

20. Schumacher S, Reineking B, Sibold J, Bugmann H (2006) Modeling the impact of climate and vegetation on fire regimes in mountain landscapes. Landscape Ecology 21: 539-554.

21. Elkin C, Gutiérrez AG, Leuzinger S, Manusch C, Temperli C, et al. (2013) A 2 C warmer world is not safe for ecosystem services in the European Alps. Global Change Biology 19: $1827-1840$.

22. Elkin C, Giuggiola A, Rigling A, Bugmann H (2015) Shortand long-term efficacy of forest thinning to mitigate drought impacts in mountain forests in the European Alps. Ecol Appl 25: 1083-1098.

23. Schaffhauser A, Curt T, Véla E, Tatoni T (2012) Fire recurrence effects on the abundance of plants grouped by traits in Quercus suber L. woodlands and maquis. Forest Ecology and Management 282: 157-166.

24. Schaffhauser A, Curt T, Tatoni T (2011) Fire-vegetation interplay in a mosaic structure of Quercus suber woodlands and Mediterranean maquis under recurrent fires. Forest Ecology and Management 262: 730-738.

25. Pausas JG, Keeley JE, Verdu M (2006) Inferring differential evolutionary processes of plant persistence traits in Northern Hemisphere Mediterranean fire prone ecosystems. Journal of Ecology 94: 31-39.

26. Pausas JG, Fernández-Muñoz S (2011) Fire regime changes in the Western Mediterranean Basin: from fuel-limited to drought-driven fire regime. Climatic Change 110: 215-226.

27. Spellerberg IF, Fedor PJ (2003) A tribute to Claude Shannon (1916-2001) and a plea for more rigorous use of species richness, species diversity and the 'Shannon-Wiener'Index. Global Ecology and Biogeography 12: 177-179.

28. Hill MO, Smith AJE (1976) Principal component analysis of taxonomic data with multi-state discrete characters. Taxon 249-255.

29. Carcaillet C, Leys B (2012) Une intime relation lie le feu et la forêt corse depuis plus de 11000 ans. Feu et foret en Corse. 